\title{
LA Filosofía JURídica de Millas: NATURALEZA Y FINES DEL DERECHO*
}

\author{
JUAN OMAR COFRÉ LAGOS**
}

RESUMEN: El trabajo que a continuación presentamos se refiere en términos generales al pensamiento jurídico de Jorge Millas. Se explica la teoría filosófica de Millas en relación con su teoría del derecho y, muy especialmente, su concepción de las relaciones entre derecho y moral. Finalmente se incursiona en su teoría axiológica del derecho y se muestran los méritos, alcances y límites de su pensamiento jurídico in genere.

PALABRAS CLAVE: Millas - Filosofía jurídica - Axiología jurídica

\section{LEGAL PHILOSOPHY OF MILLAS: NATURE AND PURPOSE OF THE LAW}

\begin{abstract}
The work presented below relates broadly the legal thought of Jorge Millas. It explains the philosophical theory of Millas regarding his theory of law and, in particular, his conception of the relations between law and morality. Finally, it is explored the axiological theory of law and shows the merits, scope and limits of legal thought "in genere".
\end{abstract}

KEY WORDS: Millas - Legal Philosophy - Legal Axiology

\section{INTRODUCCIÓN}

Jorge Millas nace en 1917 en Santiago de Chile, ciudad en la que muere en 1982. Estudia Filosofía y Derecho en la Universidad de Chile y en algunas universidades norteamericanas. Llega a ser catedrático de Teoría del Conocimiento en la Facultad de Filosofía de la Universidad de

* Este trabajo forma parte de la investigación Fondecyt 1090535 de la que el autor es investigador responsable.

Fecha de recepción: 14 de agosto de 2011.

Fecha de aceptación: 16 de enero de 2012.

** Profesor Titular de Filosofía del Derecho, Universidad Austral de Chile. Correo electrónico: jcofre@uach.cl 
Chile, y luego también catedrático de Filosofía del Derecho en la Facultad de Derecho de esa Universidad.

También fue Profesor en las universidades Iowa, Columbia y Puerto Rico. Desde 1970 y casi hasta su muerte enseña en la Universidad Austral de Chile.

Su obra filosófica, en lo fundamental, quedó publicada; en cambio, la iusfilosófica quedó inconclusa: varios artículos y, sobre todo, "apuntes de clases" para sus estudiantes de la Facultad de Derecho de la Universidad de Chile ${ }^{1}$.

Millas mantuvo un positivismo jurídico, influido por Kelsen, y desde esta doctrina general del derecho erigió su propia concepción del fenómeno jurídico, acudiendo, fundamentalmente, al pensamiento fenomenológico de Edmund Husserl, el gran pensador germano del cual toma Millas los métodos de análisis y las categorías filosóficas esenciales que aplica al derecho.

\section{1) Posibilidades y límites de la Filosofía del Derecho}

Para comprender la naturaleza y misión de la Filosofía del Derecho, es necesario, según Millas, comenzar por el concepto general de Filosofía, porque la Filosofía del Derecho, antes que Ciencia Jurídica, es disciplina filosófica, lo cual se traduce en tres consecuencias:

a. Que sus posibilidades cognoscitivas están dadas por las posibilidades del saber filosófico: esencia, fines, formas, limitaciones y métodos.

b. Que, en tanto Filosofía del Derecho, es miembro del organismo del conocimiento filosófico y es precisamente en ese saber total donde la iusfilosofía encuentra su propia situación y funciones.

c. Que las posibilidades de la Filosofía del Derecho están dadas, hemos dicho, por las posibilidades y límites de la filosofía en general. La filosofía constituye un ideal racional del pensamiento en el que se integra la experiencia bajo categorías, conceptos racionales y conexiones universales. Es tarea de la filosofía transformar el saber espontáneo en saber cons -ciente de sus posibilidades y fundamentos; cuando accedemos a un saber de esta especie, sostiene Millas que somos poseedores de un saber de comprensión. La perplejidad característica del espíritu que se siente sobrepasado y asombrado por los problemas queda superada por la explicación racional, y entonces, y solo entonces, estamos en posesión de la verdad.

1 En 2012 aparecerá publicada por la Editorial Universidad Diego Portales, y editada por el autor de este artículo, la obra inédita de Jorge Millas Filosofía del Derecho. Haremos referencia a esta obra por los parágrafos en la que se estructura y no por las páginas, tal cual suele ser costumbre en trabajos clásicos de filosofía. 
El Derecho es precisamente uno de esos objetos de pensamiento o de la experiencia que desafía la inteligencia y la deja sumida en la perplejidad con preguntas como: ¿qué es el derecho?, ¿qué función cumple?, ¿por qué obliga?, ¿cuál es su naturaleza?, ¿cómo se aplica correctamente?, ¿cómo se relaciona y distingue de la justicia?, etcétera, preguntas todas sencillas de formular pero extremadamente difíciles de contestar y comprender en sus últimas determinaciones. Igualmente, es cuestión enteramente filosófica, no solo preguntarse qué son las cosas y cómo son, sino también cuál es su último fundamento, cómo se explica su ser y su existencia en último y final extremo. Pero también es cuestión esencial del indagar filosófico preguntar cómo conocemos y cuáles son las capacidades y competencias de nuestro aparato cognoscitivo. En definitiva, qué es el conocimiento y cómo se articula y organiza para aportar explicaciones y acceder a la verdad. Todo ello, y sin olvidar que, además, en los últimos siglos se han sumado dos regiones a la investigación filosófica: el lenguaje y los valores. El lenguaje es de gran importancia porque no es posible pensar ni menos vincular lo pensado al mundo real, sea este empírico, ideal, ficticio o emocional, sino por intermedio de él. Millas se ocupa y tiene presente en su exposición iusfilosófica todos estos aspectos. Describe, siguiendo a Husserl, también una propedéutica lingüística, ya que se da cuenta que antes de armar el discurso hay que entrar en armonía con el lenguaje, conocerlo para dominarlo, y sacarle un mejor servicio.

Se puede decir que el principal intento iusfilosófico de Millas consiste y va encaminado a construir su propia axiología jurídica. En lo esencial su filosofía del derecho aspira a ser una axiología jurídica objetivista.

\section{2) FUENTES IUSFILOSÓFICAS DE MiLlaS}

Desde el punto de vista filosófico, Millas se siente a gusto con la idea de filosofía que describe Kant, aunque recibe también la influencia del pragmatismo norteamericano.

Desde el punto de vista metodológico, Millas hace suyo el método fenomenológico de Husserl y las ideas clave de la Lógica de este autor que describe las significaciones del discurso lógico-lingüístico como "idealidades" a priori.

Como iusfilósofo, acepta, en lo esencial, la teoría jurídica de Kelsen pero sostiene que es una filosofía incompleta. Incompleta, porque pasa

Husserl, Edmund (1929). Investigaciones Lógicas. Vol. I. "Prolegómenos a la lógica pura". Traducción de García Morente, Manuel y, Gaos, José (original de 1900). Madrid: Alianza Editorial, p. 38 . 
por alto distinciones filosóficas que es necesario puntualizar y, además, porque margina -sin buenas razones- la metafísica y la ontología jurídicas y, sobre todo, la axiología jurídica, disciplina iusfilosófica de la cual Millas construye su entramado y echa sus fundamentos.

Curiosamente, la obra de Hart y su "escuela" parece no haber sido conocida por Millas o, tal vez, no despertó su interés. Ni siquiera la obra de Wittgenstein tiene un mínimo lugar en su pensamiento. Esto hay que tenerlo presente a la hora de conocer y considerar sus ideas.

\section{3) IDEA DE LA Filosofía DEL DERECHO}

Hasta la década del 50 del siglo pasado se discute todavía, como un problema central, cuál es el verdadero fundamento último del conocimiento lógico. La filosofía alemana, después de vacilar, por influencia del pensamiento inglés, se decanta, precisamente por influencia de Kant, Frege y Husserl, entre otros, por un fundamento "puro", total y absolutamente ajeno a la experiencia. Por tanto, la lógica no es psicología, no es sociología, no es ciencia natural; es un conjunto sistemático de juicios analíticos, formales, puros y a priori ${ }^{3}$.

Conforme con esta tradición, las ciencias jurídicas no estudian hechos o fenómenos reales (p.e., de conducta) y no se plantean, ni epistemológicamente pueden hacerlo, preguntas acerca de sucesos o cambios del mundo factual.

Por tanto, al jurista no le compete en cuanto jurista, ninguna tarea de carácter explicativo. Explicar -sostiene Millas- significa predecir en virtud del conocimiento de leyes generales qué hechos habrán de seguir en la experiencia a tales otros hechos ${ }^{4}$.

La Ciencia Jurídica trata, en cambio, del mundo normativo. Su objeto propio son las normas y las normas, como ya enseñaron Kant, Ihering y Kelsen, nada tienen que ver con la causalidad.

Tampoco son problemas jurídicos, en sentido estricto, los relativos a las conexiones aplicables de las normas para determinar la realidad de los hechos. Esta, que es ocupación de los jueces, no es ciencia sino oficio.

Lo sorprendente es, entonces, que Millas va a sostener que las ciencias jurídicas son demostrativas en el sentido de la matemática y de la lógi-

3 Kant, Immanuel (2006). Crítica de la razón pura. Traducción de Ribas, Pedro. México D.F.: Editorial Taurus, pp. 102-296; Frege, Gotlob (1972). Lógica y Semántica. Traducción de Gómez-Lobo, Alfonso. Valparaíso: Ediciones Universitarias de Valparaíso; Husserl (1929), p. 38.

$4 \quad$ Millas, Jorge (2011). Filosofía del Derecho. Santiago de Chile: Editorial Universitaria, VI, 2 . 
ca aunque, claro, reconociendo la diferencia esencial del contenido de sus enunciados.

Los juristas (civilistas, penalistas, etc.) se ocupan, o tal vez "debieran ocuparse" para ser fiel al pensamiento de Millas, de la determinación del sentido y la aplicabilidad de las normas jurídicas. De esta idea Millas deriva dos clases de proposiciones:

i. Proposiciones que establecen relaciones lógicas entre normas generales $\mathrm{y}$,

ii. Proposiciones que establecen relaciones entre normas generales y normas singulares aplicables a situaciones concretamente individualizadas 5 .

Esta propuesta de Millas respecto del estatus científico de la ciencia jurídica parece derivarse de la idea que el propio Husserl sostuvo acerca de los saberes normativos. De ahí que Millas afirme que "toda proposición científica, cualquiera sea la ciencia que la formule, es una proposición fundada, es decir, pertenece a un repertorio de proposiciones enlazadas entre sí por nexos lógicos rigurosamente determinables. Un aserto no es científico sino por su relación con otros asertos: axiomas, definiciones, hipótesis, leyes generales." Ahora se comprende mejor por qué Millas postula que la ciencia jurídica es demostrativa.

\section{4) Algunas ideas Centrales de la Filosofía Jurídica de Millas}

Hecha esta descripción general de la idea que Millas expone acerca de la naturaleza y misión de la Filosofía del Derecho y de la Ciencia Jurídica, pasemos a exponer algunas de sus ideas centrales.

\section{1.) QUÉ ES EL DERECHO}

A Millas le parece que lo que Kelsen ${ }^{6}$ ha hecho es construir sobre todo un riguroso método de conocimiento y de análisis jurídico, pero adolece de una idea imperfecta de Derecho. La pregunta que interroga

Millas (2011) Cap. VII: "El orden normativo".

Kelsen, Hans (1994). Teoría Pura del Derecho. Traducción de Nilve, Moisés. Buenos Aires: Editorial EUDEBA. Y (1955) Teoría General del Derecho y del Estado. México D.F: Editorial Universidad Nacional Autónoma de México. Estas son las dos obras principales de Kelsen que Millas tiene en mente a la hora de formular su propia teoría jurídica y criticar el pensamiento kelseniano. 
por la esencia del Derecho - por lo que el Derecho es- sigue siendo interesante y no debe ser abandonada ni marginada al menos por dos razones: primera, porque sin saber lo que la cosa es, mal podremos saber la función de la cosa y menos aún su finalidad. Segunda, si averiguamos lo que el Derecho es, estaremos en condiciones de distinguir rigurosamente el Derecho de la Moral y la Ley de la Justicia.

Millas definirá en términos lógicos, y no metafísicos, "esencia". En efecto, "esencia" es la estructura formal, fija e invariante que caracteriza un conjunto de cosas o casos concretos. Por tanto, por esencia del Derecho debe entenderse la identidad ideal de todos los casos particulares del Derecho, tanto reales como posibles, es decir, los que han tenido lugar en la experiencia y aquellos que no habiéndolo tenido, pueden llegar a tenerlo.

La esencia es, pues, una idealidad y como ocurre que todos los entes son en el ser, el Derecho en tanto ente real o existencial (sistema normativo concreto) tiene su ser propio, es decir, su esencia.

Es de interés recordar que la fenomenología postula que, además del conocimiento deductivo y del inductivo, existe el conocimiento intuitivo. La intuición fenomenológica es eidética ${ }^{7}$, y más original y segura que cualquier otra forma de conocimiento. El conocimiento que nos procura el análisis fenomenológico conduce a esencias, y estas son "a priori" (no en el sentido kantiano); no se derivan de la experiencia, por el contrario, hacen posible su comprensión. En concordancia subordinada con Husserl, Millas dirá que el conocimiento de la experiencia jurídica nos presentará, pues, ejemplarizaciones del Derecho, modalidades de su existencia, pero no puede agregar ni quitar absolutamente nada a su contenido; este se da plenamente en un solo caso singular, se deja intuir en una sola instancia. Me bastaría a mí observar el orden jurídico de una sola comunidad para intuir la esencia del Derecho, asegura Millas.

¿Y de qué es de lo que toma nota el conocimiento de la experiencia jurídica? Pues de que existen normas de convivencia prescritas por la autoridad pública. Estas son normas de Derecho Positivo, y avanzando un paso más allá, habría que decir que estas normas expresan conductas posibles bajo la forma de una coordinación de facultades y deberes. Luego, la norma, bien entendida, es un esquema anticipatorio, aunque no predictivo, de modos posibles de relación entre personas, sostiene Millas.

Eidético es un adjetivo derivado del sustantivo griego "eidos", que significa "idea". Pero la idea para el pensamiento griego no tiene el sentido psicológico que comúnmente se le asigna. Por eso más bien conviene entender la expresión idea como "forma", en tanto todo contenido solamente aparece a la percepción intelectual a través de una forma, sin la cual el contenido sustancial es inaprehensible. 
Para Millas, esto no es una obviedad. Hay juristas que tienen ideas muy diferentes. Algunos confunden el Derecho con un conjunto de normas que quedan antes o más allá de la experiencia y, otros, como Cossio ${ }^{8}$, lo confunden con la conducta o comportamiento. Luego, se pregunta Millas: ¿dónde hemos de buscar la esencia del Derecho para averiguar finalmente en qué consiste, qué es? Naturalmente, como enseńa Kelsen, en la norma positiva.

Será, por consiguiente, en el mundo del pensamiento normativo en donde habremos de aprehender la esencia del Derecho. La pregunta por el ser del Derecho tiene que partir por la pregunta por el ser de las normas jurídicas ${ }^{9}$, concluirá Millas.

La norma es un esquema de lenguaje en el cual se relacionan un sujeto con un predicado. La norma, así entendida, es la expresión externa de un contenido lógico, la proposición. Por eso, no es lo mismo decir "es conveniente poner bajo custodia al paranoico" que afirmar "el paranoico debe ser puesto bajo custodia". La primera oración expresa un conocimiento, la segunda prescribe una conducta forzosa y, como se ve de inmediato, esa prescripción parece que tiene mucho que ver con la expresión deóntica "debe ser". Para descubrir qué hay de propio en las normas, Millas cree que hay que acudir al mundo de las significaciones, en el sentido husserliano. Hay diversos tipos de proposiciones normativas. Millas distingue cinco (técnicas, de trato social, prácticas, éticas y, jurídicas). Dejando de lado las tres primeras, intentaré mostrar en qué consiste el trabajo de nuestro pensador en orden a determinar con precisión lógicosemántica qué hay de propio en la norma ética, y qué de singular en la norma jurídica y, luego, describir su diferencia específica.

Millas piensa que si logra ir más allá de Kelsen en esta materia disuelve el "pseudoproblema" de las supuestas relaciones necesarias o no necesarias entre Derecho y Moral y, de paso, deja sin piso la disputa entre iusnaturalistas y positivistas.

Antes que la diferencia, lo primero que salta a la vista al contemplar ambos tipos de proposiciones, es la similitud lingüística entre ambas. El lenguaje humano parece que jamás distinguió dos expresiones para manifestar dos ideas bastante diferentes. Hay que ir más allá de la semejanza lingüística e investigar la significación del término en un contexto moral y en un entorno jurídico.

8 Cossio, Carlos (1944). La teoría egológica del derecho y el concepto jurídico de libertad. Buenos Aires: Editorial Losada. Y (1954). Teoría de la verdad jurídica. Buenos Aires: Editorial Losada.

Millas critica la teoría egológica del gran jurista argentino porque considera que confunde los hechos reales con los hechos ideales, y de este modo su fenomenología estropea cualquier teoría filosófica del derecho. Cfr. Filosofía del Derecho, op. cit. IV, 4. 
Aquí entiende por "significación" Millas, exactamente lo que entiende Husserl en su Lógica: el contenido lógico-semántico de la expresión. Millas arranca del ejercicio de Husserl que será vital para establecer su distinción.

El intento de Husserl. En su Lógica el pensador germano intentaba demostrar que todo enunciado prescriptivo en el campo de la moral podía reducirse, "salva veritate", a un enunciado descriptivo.

Supongamos un caso de un enunciado prescriptivo que rece:

- "Un soldado debe ser valiente"

Intentemos, de acuerdo con Husserl y Millas, reducir este enunciado prescriptivo a un enunciado descriptivo; quedaría de la siguiente manera:

- "Solo un soldado valiente es un buen soldado"

¿Qué consecuencias tiene esta reducción si, en efecto, como cree Husserl, y Millas acepta, es posible demostrar que la expresión deóntica desapareció, sin que, eso sí, haya desaparecido la valoración ética?

Que demostraría que en el primer enunciado hay una estimación. Quien enuncia esa proposición está diciendo que le parece bueno, deseable o valioso que el deber ser sea llevado a su plenitud en el ser. El hablante quiere que el deber ser sea llevado a la existencia como ser porque es un ser (ente) valioso. Valioso porque implica un valor que queremos ver concretado en un bien. En el valor de lo que vale hay un ideal de ser que exige de nuestra conciencia acatamiento, respeto y preferencia. ¿Qué es, entonces, lo que agrega o mienta por modo específico la categoría del deber ser? Por lo visto, dice Millas, una cosa muy importante: la imperatividad del bien. El bien es aquello que, visto como tal en su modo concreto de ser, se revela como preferible, como valioso y como obligante. Por eso bien y deber ser, son realmente lo mismo. No se puede confundir un mandato cualquiera (¡cumpla con su trabajo!) con una norma moral, porque el mandamiento expresado en el deber ser, deriva su fuerza exhortativa de la naturaleza del bien. Este mandato señala el bien de lo mandado por intuición de lo bueno, y obliga desde "dentro" de la conciencia, autónomamente, dejando intacta nuestra libertad.

En resumen, una verdadera norma ética está ontológicamente inclinada hacia el bien, y su mandato es acercarse a él. La neutralidad de la norma moral carece de sentido. Si es moral, no puede ser neutra.

A la luz de lo averiguado, veamos qué ocurre en la norma de Derecho. ¿Hay algún parentesco entre el deber ser moral y el jurídico? Desde luego, fuera del lingüístico las normas jurídicas también declaran que un 
deber ser ha de ser llevado a la categoría del ser. Cuando la Constitución chilena manda "Toda sentencia de un órgano que ejerza jurisdicción debe ser fundada en un proceso previo legalmente tramitado", ciertamente también está haciendo una exigencia, pero el asunto está en averiguar si esa exigencia es la misma que aparece en la norma moral. No cabe duda de que la norma hace referencia a un valor pero (y esto es lo original de Millas), tal norma no es en sí misma declarativa de valor. Frente a la norma "Respeta a tu prójimo" intuimos, dice Millas, un valor; en cambio frente a la norma "Paga tus impuestos" no hay intuición de valor, hay solo captación y comprensión intelectual de una exigencia heterónoma. Por eso, mientras seamos rigurosos y nos mantengamos dentro de la significación estrictamente jurídica de la norma, será inútil que apuremos su sentido para que salga de él una exigencia de valor.

Veamos esto con mayor detalle. Supongamos que una norma del Código Tributario establezca lo siguiente:

"Todo contribuyente debe declarar su renta en el mes de abril de cada año”.

Esta es, obviamente, una norma prescriptiva. Veamos si es posible hacer desaparecer la prescripción, salva veritate, y mantener el sentido de la norma original. De acuerdo con el ejercicio anteriormente aplicado a la norma moral, tendríamos el siguiente resultado: te".

"Solo un contribuyente que declara su renta es un buen contribuyen-

Millas sostendría que aquí no hay equivalencia, puesto que del mandato jurídico no se sigue, en la segunda norma, una descripción que diga y sostenga exactamente lo mismo que sostiene la norma. A nadie se le ocurriría decir que un contribuyente es "bueno", como contribuyente, por el mero hecho de que declara su renta. Luego, no habría un paralelo estricto entre el resultado del procedimiento aplicado a un caso jurídico que a un caso moral.

Bien, eso es lo que no hay en la norma de Derecho. Esa sería la diferencia específica frente a la norma moral. Pero aún nos falta saber qué hay de propio en la norma jurídica. Veamos.

Una norma del Código del Trabajo chileno dice: "Los derechos de los trabajadores son irrenunciables". Si juzgamos con criterio estrictamente jurídico, concluiremos, correctamente con Kelsen, que aquí no hay ni puede haber más que la imputación de una consecuencia a un antecedente. Esta norma -como toda norma de Derecho- establece exclusivamente una relación lógica entre antecedente y consecuente y, en realidad, viene 
a decir nudamente esto: "Los derechos de los trabajadores son irrenunciables" (norma secundaria) y, "La renuncia del trabajador a sus derechos es nula" (norma primaria).

Ni siquiera una norma penal como la del parágrafo 211 del Código Penal alemán que reza: "El asesino será castigado con pena privativa de libertad de por vida", da a entender o connota que sea malo asesinar. No. Simplemente está diciendo que si alguien asesina, sufrirá tal consecuencia.

El punto relevante de la discusión ha demostrado que el deber ser de la norma jurídica consiste únicamente, para Millas, en la exigencia de que alguien obre o deje de obrar de cierta manera, bajo apercibimiento de una determinada consecuencia o sanción. La proposición jurídica es, pues, en último extremo, una instancia de enlace hipotético de términos que revela que el no cumplimiento de un antecedente es la condición para que sea imputable una sanción. Esta tarea debida a Kelsen (y que Millas considera su principal y más brillante idea metodológica) elimina de la descripción de la norma de derecho todo elemento extrajurídico, tesis que Millas cree haber demostrado convincentemente.

En resumen, Millas sostiene que mientras las normas no jurídicas imputan valores o disvalores, y no consecuencias, las normas jurídicas imputan consecuencias y no valores.

\section{2.) EL ORDEN JURÍDICO CONSIDERADO IN TOTO}

Siguiendo también a Kelsen, Millas quiere demostrar que al examinar el mecanismo lógico de la proposición jurídica, se revela otra propiedad esencial del Derecho, esto es, de que no hay verdaderamente norma jurídica, sino normas (en plural). Sostiene entonces Millas que cuando se consideran las normas en la plenitud de su ser jurídico (como elementos de un sistema), es posible reconocer en ellas tres cualidades fundamentales: juridicidad, validez y eficacia.

La juridicidad depende de la forma lógica de la norma que se caracteriza por la imputación de una consecuencia a un antecedente bajo la forma de un complejo conjuntivo de juicios hipotéticos; el contenido específico de esta norma, su significación propiamente tal, diría Millas, se reduce a la exigencia de una conducta bajo la forma de deber ser.

Por otra parte, Millas acepta el concepto de validez de Kelsen aunque, como se verá, piensa que no es suficiente para explicar por qué obedecemos al Derecho y cuál es su verdadera génesis. Sí insiste, en cambio, en que no hay parentesco alguno entre el aspecto moral de la vida humana y la validez jurídica. Es preciso señalar, dice, "la identificación inadmisible de los conceptos jurídicos y axiológicos de valor", a propósito de 
la teoría de otro autor chileno ${ }^{10}$ que sostiene que hay una zona común y, por tanto, un contenido moral ínsito en la validez jurídica.

$\mathrm{Y}$, también, Millas sigue a Kelsen en su idea de eficacia; mientras la validez es el deber ser u obligatoriedad de la norma, la eficacia, en su grado de cumplimiento, es el grado de correspondencia entre la conducta requerida y la conducta realizada. Representa, así, una conexión entre los dominios del ser y del deber ser.

Para determinar la validez, es decir, la existencia de la norma, no hace falta que sepamos si esta es eficaz o no. Basta solo que pertenezca a un orden jurídico existente, etc., pero también es claro que aunque la validez no depende de la eficacia de la propia norma, sí depende del orden jurídico total, considerado como un todo ${ }^{11}$.

A partir de este momento Millas comienza a interesarse por el ser, o lo que él llama la esencia del Derecho, pero no de la norma en tanto norma, sino del conjunto total que constituye el ordenamiento. Comparte con Kelsen la idea de que el Derecho en su conjunto es un instrumento al servicio de concepciones o valores políticos, sociales, económicos, etc.; es decir, que el Derecho es, en definitiva, una modalidad específica del poder político, un instrumento. Desde esta perspectiva el orden normativo es una suerte de unidad teleológica de ideales y principios filosóficos que determinan el contenido particular de la norma y que informan el orden jurídico en general. El Derecho es, entonces, en esencia, un mecanismo de acción puesto al servicio de un ideal de vida. Este ideal es un complejo repertorio de valores en donde la justicia no es necesariamente el valor principal o dominante. Hay muchos otros valores que una sociedad quiere que se realicen y para ello llama al Derecho para que este contribuya a su consolidación. Millas en esto quiere ir más allá de Kelsen, puesto que el jurista vienés se contenta con concebir el Derecho como un instrumento destinado a conseguir la realización de los valores dominantes de una sociedad.

Ahora Millas se pregunta cuál es la fuente última de la obligación jurídica y es aquí donde intenta encontrar y dotar al Derecho de un fundamento real y extrajurídico. Primero, rechaza las respuestas transcenden-

10 Hübner Gallo, Jorge (1951). Introducción a la teoría de la norma jurídica. Santiago de Chile: Editorial Jurídica de Chile. Este autor sostiene, efectivamente, que las normas jurídicas en sí mismas poseen un contenido de carácter moral, y que, en determinados casos, no es posible discernir entre lo estrictamente jurídico y lo estrictamente moral. Así, por ejemplo, la norma del Código Penal que castiga el homicidio implica una carga axiológica insoslayable. Como se ve, exactamente lo contrario de lo que sostiene nuestro autor.

11 Millas (2011). VIII, 1-10; también se refiere a esta doctrina Millas (1956) en "Sobre los fundamentos reales del orden lógico-formal del derecho". Revista de Filosofía. Sumario del $\mathrm{N}^{\circ}$ 3. Universidad de Chile; y véase también (1982) "Los determinantes epistemológicos de la teoría pura del derecho". Teoría pura del derecho. Jornadas académicas. Valparaíso: Editorial Edeval. 
talistas características del iusnaturalismo racionalista o teológico. También rechaza las respuestas empiristas que buscan en los hechos reales, generalmente de carácter psicológico, el fundamento último de validez de la norma, por ejemplo, de la norma constitucional. Y en este punto Millas también se separa de Kelsen y quiere ir más allá de él. Dice el jurista chileno que Kelsen en su riguroso y consistente intento de eliminar todo elemento extrajurídico de la interpretación del Derecho, radicaliza las cosas y llega a sostener que la obligatoriedad de las normas, y la voluntad de quien las engendra, son elementos separables, hasta el punto de que aquella no es en ningún sentido el fundamento de esta. Veamos todo esto con un poco mas de detalle.

Millas se propone ahora una tarea más. Nuevamente reconoce que Kelsen se ha acercado a la explicación más convincente. En efecto, el análisis kelseniano ha pretendido demostrar que la voluntad, es decir, el efectivo querer de tales o cuales contenidos normativos, puede separarse de la obligatoriedad o validez de la norma de modo tal que esta se constituye y subsiste independientemente de aquella.

Sin embargo, la Teoría Pura no lograría explicar en definitiva la obligatoriedad del Derecho. El error de Kelsen consistiría, asegura Millas, en creer que basta el carácter puramente formal o lógico de la norma y que, por tanto, se puede concebir la obligatoriedad sin consideración alguna de la voluntad o querer individual o colectivo.

Millas sostendrá que esta tesis es contraria a la experiencia, debido a que Kelsen ha olvidado que el Derecho es un fenómeno de la praxis y, por tanto, sus categorías explicativas no pueden ser solamente teoréticas, sino también han de ser prácticas. Kelsen sostiene que la validez deriva de otras normas válidas, generalmente las constitucionales que disponen cómo entran en vigencia y cómo se derogan las leyes. Así se explica, entonces, que no obstante haberse dejado de querer, sus contenidos sigan obligando. Es verdad que las normas valen porque valen otras normas, pero tratándose de la Constitución, la validez ya no es derivativa, ya no es una propiedad lógico-formal; se convierte en un hecho. Ahora su validez depende de la eficacia.

Y para que opere la eficacia se requiere un acto de voluntad; la voluntad es un acto de querer y sin este querer no es posible que la Constitución sobreviva.

Con mayor precisión, lo que se quiere no es tal vez que este o aquel contenido constitucional valga y se aplique sino, de manera general, lo que realmente se quiere, como condición de validez, es que como un todo la Constitución siga valiendo. Por tanto, la validez de las normas se halla, en último extremo, supeditada al orden jurídico total. Entonces, más allá del límite de las relaciones de validez de la norma, el querer real aparece 
como un supuesto básico del Derecho. Así, pues, tras toda la maquinaria jurídica hay un acto de voluntad que sustenta y hace posible el Derecho.

¿En qué consiste este acto de voluntad? En un querer colectivo específico a favor de la paz, la justicia, el orden, etc. Kelsen ha eliminado la voluntad como fundamento de la norma y ello es correcto mientras nos atengamos a su validez que, al decir de Millas, es una relación puramente formal entre regiones limitadas del campo jurídico. Sin embargo, basta con traspasar el límite de la validez y considerar la totalidad, y no solo las regiones, y la existencia, y no la mera esencia de la norma, para descubrir que la validez se confunde con la eficacia y que, en definitiva, el orden jurídico se sostiene por la voluntad efectiva de un pueblo, de un grupo de poder, e incluso de un gobernante autocrático.

Naturalmente que Millas se da cuenta que esta tarea plantea un serio problema: el querer, la voluntad, son hechos y un hecho puede explicar otros hechos, como se ha visto, pero de un hecho no se puede derivar un deber. Por tanto, el fenómeno del querer colectivo no puede explicar por qué obliga el Derecho.

Tampoco hasta aquí Kelsen nos propone una buena respuesta, si ya no consideramos las normas individualmente, sino el Derecho como un todo. Es obvio para Millas que al alcanzar las normas supremas o constitucionales, la obligatoriedad del Derecho tiende a perder su carácter derivativo, puramente formal: en la última estación de su recorrido Kelsen postula que las normas de grado supremo derivan su validez del principio "obedece al primer legislador", y ahí detiene su análisis. Finalmente, por tanto, esta norma fundamental vendría a ser la condición formal de la obligatoriedad a las normas que a partir de ellas se derivan.

La norma fundamental le permite a Kelsen alcanzar el límite de esta exigencia pues, aunque aquella no es una norma positiva, pertenece al orden jurídico como ingrediente lógico necesario de su estructura. Si no estuviéramos obligados a obedecer al primer legislador, ninguna norma sería formalmente obligatoria.

Eso por lo que respecta a la Teoría Pura que fija ahí su límite máximo de interés científico. Pero si la Filosofía es el ejercicio del pensamiento en el límite, como enseńa Millas, se ve enseguida que el análisis filosófico va más allá de la norma categorial y esto, porque es evidente que nada nos impide preguntar, a su turno, ¿por qué obliga la norma categorial?, ¿por qué debemos obediencia al primer legislador?

Millas cree que la norma categorial solo es un supuesto "a priori" del conocimiento jurídico, pero otra cosa es el Derecho como sistema normativo práctico. La norma categorial solo podría ser un último fundamento "a priori" si tuviera el carácter imperativo, sostiene Millas, de un imperativo categórico o de un deber axiológico que se imponga a la conciencia humana por intuición, al modo como se imponen los objetos valiosos. 
Tampoco se impone a la conciencia racional como lo hacen los principios y axiomas de las ciencias formales, que obligan a pensar de esa manera y no de otra, constrińendo al pensamiento a reconocer la verdad de la aserción (por ejemplo, no podemos rechazar el principio de no contradicción sin contradecirnos). En el campo jurídico no es el caso. ¿Cuál es el caso, entonces? Si se considera el Derecho "in toto" ${ }^{2}$, claramente ya no es posible encontrar en sus propios elementos sistemáticos el fundamento de su obligatoriedad. El fundamento del Derecho se halla, pues, dice Millas, en cosas extrajurídicas. ¿En qué cosas? "Es evidente, sostiene, que el fundamento de la obligatoriedad del orden jurídico se halla en el poder que lo sustenta”. El poder es la condición posibilitante del Derecho. ¿Dónde reside, entonces, la fuente última de obligatoriedad del Derecho "in toto"? Pues en la intuición axiológica de los valores que persigue y, en definitiva, lo sustenta. "El Derecho "in toto", sostiene, como idea de un orden de convivencia regido por la autoridad pública e independientemente de sus particulares modalidades, nos obliga en cuanto él mismo es un valor (subrayo)". Es decir que debemos acatamiento al Derecho porque es un bien. El Derecho es una cosa valiosa.

De este modo queda claro para Millas, contra Kelsen, que el Derecho no puede fundar su propio deber ser. El Derecho obliga porque es un bien y la norma categorial se sostiene por un imperativo axiológico.

\section{3.) Problemas Que Suscita la teoría de Millas}

A continuación esbozaré algunos puntos que me parecen débiles en el pensamiento de Millas y que pueden dar origen a una discusión y a enriquecer el debate:

El análisis de la norma jurídica -en relación con la norma moral, como hemos visto- no deja claro, como quiere Millas, que una y otra nada tengan que ver desde el punto de vista de su contenido normativo.

No parece razonable, por ejemplo, que la norma que castiga el homicidio o la violación, esté exenta de toda carga moral y que sea, en ese sentido, axiológicamente neutra. No puede querer ese mismo "querer colectivo" que el legislador promulgue esa norma única y exclusivamente por razones de validez formal. Millas parece olvidar que cuando el legislador legisla, lo hace teniendo al frente un cierto sentido de corrección moral $^{13}$, sin que entremos, naturalmente, a discutir qué es lo que ha de

MiLlas. (2011) Capítulo VIII "El problema de la obligatoriedad del derecho".

Alexy, Robert (2005). La institucionalización de la justicia. Edición y traducción de Seoane, José Antonio; Sodero, Eduardo Roberto y Rodríguez, Pablo. Granada: Editorial Comares. En esta obra se recogen varios trabajos del autor alemán en el cual plantea la teoría de la 
entenderse por "bueno" o por "malo". Ese es un tema totalmente ajeno a nuestra discusión.

En mi opinión, la norma jurídica no es en sí axiológicamente neutra, y la cópula deóntica deber ser no expresa solamente una relación lógica. Parece incluir, también, un elemento de moralidad.

Millas considera que el Derecho es instrumental y solo instrumental, que su función es transitiva. Ya verá cada pueblo qué hace con ese instrumento. El Derecho está compuesto de normas, cada una de las cuales es axiológicamente neutra. Pero si eso es así, ¿cómo llega Millas a derivar de estos antecedentes que el Derecho "in toto" es un bien, un valor?

$\mathrm{Si}$ a través del Derecho se consiguen objetivos valiosos, y el Derecho en sí mismo es valioso, ¿por qué sus normas no son valiosas? ¿Cómo van a ser axiológicamente neutras si pertenecen a un todo que no es axiológicamente neutro? Esta es una dificultad interna de su teoría que no queda suficientemente explicada en los trabajos del autor chileno.

Por otro lado, Millas acepta la idea de Kelsen de acuerdo con la cual el derecho debe ser concebido como un instrumento social. Pero si aceptamos que es un instrumento, entonces también debemos aceptar que los instrumentos en sí mismos no tienen un valor sustantivo, sino meramente transitivo, como el mismo Millas afirma y sostiene. Luego, si el derecho es un instrumento, considerado en su conjunto, no puede ser al mismo tiempo "valioso in toto". Más bien, las cosas serían como las postula Kelsen al sostener que "cualquier contenido puede ser derecho". Por cierto que esto último suena moralmente duro, pero hay que reconocer que jurídicamente hablando es más coherente con la teoría instrumental. Los instrumentos no son buenos ni malos en sí mismos, sino que lo son en la medida que sean usados para conseguir el bien o el mal colectivo. Eso depende de la intención de quién lo use, porque el instrumento mismo, intrínsecamente hablando, carece de intención. Es una forma sin alma, por decirlo así.

A no ser que postulemos que hay al menos algunos instrumentos que sin dejar de ser instrumentos sean también en sí mismos valiosos. Sería por ejemplo el caso de la medicina. Se podría postular que la medicina es un instrumento y que solamente está al servicio del bien (devolver la salud y mitigar el dolor). Es decir, si la medicina, como ciencia, fuera utilizada para hacer el mal, ipso facto dejaría de ser medicina y se transformaría en una suerte de antimedicina. ¿O es que acaso se podría afirmar que aun la medicina de Mengele sigue siendo medicina?

Otro tanto se podría decir del derecho. Para que la idea de Millas resulte coherente - esto es, que el derecho es bueno in toto- habría que

corrección jurídica, corrección que en última instancia encuentra su fundamento, según el jurista germano, en una cierta idea de corrección moral. 
sostener que el derecho deja de ser derecho en la misma medida que se separa de los valores que contiene y que persigue. Estos no podrían ser otros que los valores eternos defendidos en todos los tiempos y en todos los lugares, llamados derechos humanos, y hoy día incorporados al derecho positivo con el nombre de derechos fundamentales. Pero, entonces, la consecuencia es que las normas jurídicas, o al menos algunas de ellas (especialmente las penales) tomadas individualmente o en "paquetes", deben ser concebidas como jurídicas y morales al mismo tiempo. Si no son morales, no tienen valor y si los elementos de un conjunto no tienen una determinada nota, entonces el conjunto tampoco puede exhibir dicho atributo.

En definitiva, percibo una tensión permanente entre la idea de la norma jurídica individualmente considerada como privada de valor, y el sistema jurídico in toto como dotado de valor. Parece que Millas siempre estuvo consciente de esta "contradicción", pero sus intentos de aplacarla, rigurosamente hablando, no arrojan resultados convincentes. El mismo concepto de seguridad jurídica, que él trabaja originalmente, pierde fuerza en la medida que lo considera por un lado un valor pero, por otro, elemento esencial de un sistema jurídico. ¿De dónde va a sacar su valor si pertenece a un sistema instrumental y los valores, por definición, no se dejan instrumentalizar?

Estas y otras cuestiones del mayor interés son abordadas por el pensamiento jurídico de Millas. Hay sin duda en su doctrina jurídica aportes rigurosos y valiosos a la filosofía y a la teoría del derecho, no obstante lo cual hay también oscuridades y debilidades conceptuales y sistemáticas sobre las que conviene volver para seguir avanzando en la dirección indicada por el maestro.

\section{BIBLIOGRAFÍA}

- Alexy, Robert (2005). La institucionalización de la justicia. Edición y traducción de Seoane, José Antonio; Sodero, Eduardo Roberto y Rodríguez, Pablo. Granada: Editorial Comares.

- Cossio, Carlos (1944). La teoría egológica del derecho y el concepto jurídico de libertad. Buenos Aires: Editorial Losada.

- Cossio, Carlos (1954). Teoría de la verdad jurídica. Buenos Aires: Editorial Losada.

- Frege, Gotlob (1972). Lógica y Semántica. Traducción de GómezLobo, Alfonso. Valparaíso: Ediciones Universitarias de Valparaíso.

- Husserl, Edmund (1929). Investigaciones Lógicas. Vol. I. "Prolegómenos a la lógica pura". Traducción de García Morente, Manuel y Gaos, José (original de 1900). Madrid: Alianza Editorial. 
- Hübner Gallo, Jorge (1951). Introducción a la teoría de la norma jurídica. Santiago de Chile: Editorial Jurídica de Chile.

- Kant, Immanuel (2006). Critica de la razón pura. Traducción de Ribas, Pedro. México D.F.: Editorial Taurus.

- Kelsen, Hans (1994). Teoría Pura del Derecho. Traducción de Nilve, Moisés. Buenos Aires: Editorial EUDEBA.

- Kelsen, Hans (1955) Teoría General del Derecho y del Estado. México D.F: Editorial Universidad Nacional Autónoma de México.

- Millas, Jorge (2011). Filosofía del Derecho. Santiago de Chile: Editorial Universitaria, VI, 2.

- Millas, Jorge (1956) en "Sobre los fundamentos reales del orden lógico-formal del derecho". Revista de Filosofía. Sumario del $\mathrm{N}^{\circ} 3$. Universidad de Chile;

- Millas, Jorge (1982) "Los determinantes epistemológicos de la teoría pura del derecho". Teoría pura del derecho. Jornadas académicas. Valparaíso: Editorial Edeval. 